\title{
RAGAM BAHASA PEDAGANG SAYUR DI PASAR KIDUL DUSUN BLOKAGUNG DALAM RANAH FONOLOGI
}

\author{
Yulia Dwi Oktafiani \\ e-mail: yuliadwioktafiani111@gmail.com \\ Prodi Tadris Bahasa Indonesia \\ IAI Darussalam Blokagung Banyuwangi
}

\begin{abstract}
Abstrak
Tujuan dari penelitian ini adalah mampu mendeskripsikan hasil ujaran pedagang sayur di Pasar Kidul Dusun Blokagung dalam ranah fonologi dan juga mampu mengetahui faktor yang menyebabkan adanya ragam bahasa para pedagang.

Metode yang digunakan adalah deskriptif kualitatif. Metode yang tidak membutuhkan hitungan angka dan digunakan untuk menggambarkan atau menuliskan kejadian-kejadian pada saat penelitian dilaksanakan. Data dan sumber data yang dibutuhkan dalam penelitian ini berupa kata, frasa, kalimat dalam ujaran pedagang sayur di pasar kidul Dusun Blokagung.

Hasil penelitian menjabarkan ragam bahasa dari ujaran pedagang sayur ditinjau dari kajian fonologi. Terdapat perubahan fonem (agar pembeli mendengar dengan jelas jenis sayur yang ditawarkan), penghilangan fonem (untuk mempercepat pedagang menyampaikan tuturan ketika menawarkan sayurnya), penambahan fonem (untuk kelancaran pedagang dalam bertutur) maupun pengurangan fonem (untuk kelancaran pedagang dalam bertutur). Sehingga tujuan pedagang menawarkan sayurnya dapat dilakukan dengan baik dan diterima oleh pembeli. Dari penelitian ini didapatkan tiga faktor yang menyebabkan ragam bahasa, yaitu faktor kebiasaan, menarik perhatian penjual, dan faktor cepat terjual.
\end{abstract}

Kata Kunci: Ragam Bahasa, Fonologi

\begin{abstract}
The purpose of this study is to be able to describe the results of the utterances of vegetable traders in the kidol market of Blokagung sub-village in the phonological domain and also be able to find out the factors that cause the various languages of the traders.

The method used is descriptive qualitative. The method does not require a count of numbers and is used to describe or write down events at the time the research was conducted. Data and data sources needed in this study are in the form of words, phrases, sentences in the utterances of vegetable traders in the kidul market of Blokagung hamlet.

The results of the study describe the various languages of the vegetable traders' utterances in terms of phonological studies. There are phoneme changes (so buyers can hear clearly the types of vegetables offered), phoneme removal (to speed up traders delivering speech when offering their vegetables), phonemes additions (for fluent traders in speaking) and phonemes reduction (for fluent traders in speaking). So that the purpose
\end{abstract}


of traders offering vegetables can be done well and accepted by the buyer. From this research, there are three factors that cause a variety of languages, namely the habit factor, attracting the attention of the seller, and the factor of quickly selling.

Key words: various languages, phonology.

\section{A. Pendahuluan}

Dalam hubungannya dengan masyarakat, maka akan dikenal dengan istilah ragam bahasa karena banyaknya pelaku komunikasi yang berbeda budaya. Ragam bahasa dapat ditandai dengan ciri-ciri linguistik tertentu, seperti fonologi, morfologi, dan sintaksis.

Kemudian ragam bahasa juga dapat ditandai dengan ciri-ciri nonlinguistik, seperti lokasi atau tempat penggunaannya, lingkungan sosial pemakaiannya, dan lingkungan profesi yang bersangkutan. Ragam bahasa akan dijumpai atau akan ditemukan di tempat yang terdapat banyak masyarakat pemakai bahasa. Di Dusun Blokagung Desa Karangdoro terdapat dua pusat perbelanjaan atau pasar yang berbeda nama.

Ragam bahasa tersebut dapat dilihat pada pedagang sayur di Pasar Kidul Desa Blokagung saat menjajakan dagangannya dan juga berkomunikasi saat tawar menawar antara penjual dan pembeli.

Masyarakat yang beraneka ragam serta lingkungan budaya yang berbeda menyebabkan ragam bahasa dalam penggunaan bahasa. Ragam bahasa dalam penggunaan bahasa yang dimaksud adalah tidak seragamnya bahasa yang ada dalam suatu lingkungan atau masyarakat.

Ragam bahasa muncul karena adanya suatu kebutuhan penggunaan bahasa untuk berkomunikasi dan bekerjasama sesuai dengan situasi dan fungsi dalam kontak sosialnya. Terdapat dua pandangan mengenai variasi bahasa, yaitu berdasarkan penutur bahasa dan bahasa berdasarkan fungsinya dalam masyarakat. Penutur yang homogen, etnis, status sosial sama berarti bahasa itu akan menjadi seragam. Sebaliknya, jika masyarakat beraneka ragam bahasa akan berbeda-beda sesuai dengan fungsinya untuk berinteraksi dalam masyarakat.

Alasan peneliti memilih judul atau objek ini, karena peneliti pernah mengalami suatu peristiwa di sebuah pasar yaitu berupa ketidakpahaman peneliti 
terhadap kata yang diucapkan oleh penjual. Karena rata-rata penjual berasal dari suku madura dan peneliti berasal dari Suku Jawa, maka peneliti tidak dapat memahami bahasa yang digunakan oleh si penjual. Kemudian peneliti juga ingin mengetahui sebenarnya mengapa bahasa yang digunakan berbeda-beda dan kaitannya dengan asal kata bagaimana bisa menghasilkan kata yang yang sedikit berbeda dari asalnya seperti kata yang memili fonem vokal /i/ bisa berubah menjadi /e/.

Peneliti membahas ragam bahasa pedagang sayur di pasar kidul desa Blokagung, yaitu: pertama yaitu ciri khas kata yang dihasilkan pedagang sayur saat menawarkan barang dagangannya berbeda dan menarik untuk diteliti. Kemudian dalam pengucapan kata oleh pedagang sayur menimbulkan tuturan yang berbeda sehingga akan memperkaya ragam bahasa.

\section{B. Metode Penelitian}

Pada penelitian ini, digunakan penelitian deskriptif kualitatif. Rofiq (2021:48) menyatakan bahwa penelitian deskriptif kualitatif merupakan suatu penelitian yang datanya secara kualitatif dan penjabarannya secara deskriptif.Menurut M. Zaim (2014: 13) metode kualitatif mencerminkan suatu perspektif fenomenologis, yaitu penelitian yang berusaha untuk memahami makna dari peristiwa-peristiwa dan interaksi-interaksi manusia dalam situasi tertentu. Menurut Sudaryanto (1993: 25) dalam skripsi Isti Ainurrahma berpendapat bahwa metode deskriptif adalah metode atau cara kerja dalam penelitian yang sematamata hanya berdasar pada data empiris berupa bahasa yang sifatnya seperti apa adanya. Maka penelitian ini mendeskripsikan ciri ragam bahasa oleh penutur asli, yaitu para pedagang sayur yang menawarkan dagangannya dengan bahasa secara apa adanya di Pasar kidul Dusun Blokagung.

Data penelitian ini berupa tuturan yang dipakai atau dihasilkan oleh pedagang sayur saat menawarkan dagangannya atau saat berkomunikasi dengan pembeli dan sumber data pada penelitian ini adalah pedagang sayur di pasar kidul Dusun Blokagung.

1. Jenis penelitian 
Pada penelitian ini, digunakan penelitian deskriptif kualitatif. Menurut M. Zaim (2014: 13) metode kualitatif mencerminkan suatu perspektif fenomenologis, yaitu penelitian yang berusaha untuk memahami makna dari peristiwa-peristiwa dan interaksi-interaksi manusia dalam situasi tertentu. Menurut Sudaryanto (1993: 25) dalam skripsi Isti Ainurrahma berpendapat bahwa metode deskriptif adalah metode atau cara kerja dalam penelitian yang semata-mata hanya berdasar pada data empiris berupa bahasa yang sifatnya seperti apa adanya. Maka penelitian ini mendeskripsikan ciri ragam bahasa oleh penutur asli, yaitu para pedagang sayyang menawarkan dagangannya dengan bahasa secara apa adanya di Pasar kidul Dusun Blokagung.

2. Data dan sumber data

Data penelitian ini berupa tuturan yang dipakai atau dihasilkan oleh pedagang sayur saat menawarkan dagangannya atau saat berkomunikasi dengan pembeli.

Sumber data pada penelitian ini adalah pedagang sayur di pasar kidul Dusun Blokagung.

3. Teknik Pengumpulan Data

Pada penelitian ini, peneliti menggunakan teknik pengumpulan data dengan cara wawancara. Esterberg (2002) dalam Sugiyono (2019: 304) mendefinisikan wawancara atau interview sebagai berikut. "a meeting of to persons to exchange information and idea through question and responses, resulting in communication and joint construction of meaning about a particular topic". Yaitu, wawancara adalah merupakan pertemuan dua orang untuk bertukar informasi dan ide melalui tanya jawab, sehingga dapat dikonstruksikan makna dalam suatu topik tertentu. Maka dengan wawancara peneliti akan mengetahui serta mendapatkan hal-hal yang lebih mendalam pada objek yang dituju.

Supaya hasil wawancara dapat terekam dengan baik, maka dibutuhkan alat untuk melaksanakan wawancara, yaitu:

a. Buku catatan, berfungsi untuk mencatat semua percakapan dengan sumber data. Dalam hal ini, buku catatan digunakan untuk mencatat percakapan dengan pedagang sayur yang merupakan sumber data pada penelitian ini. 
b. Tape recorder, berfungsi sebagai perekam suara. Maka pada penelitian ini tape recorder digunakan sebagai alat untuk merekam percakapan dengan pedagang sayur.

c. Camera, berfungsi untuk mengambil gambar. Pengambilan gambar dilakukan pada peneliti yang sedang atau telah selesai melakukan pembicaraan dengan narasumber atau sumber data. Dengan adanya foto, maka dapat meningkatkan keabsahan sebuah penelitian karena terbukti peneliti benar-benar melakukan pengumpulan data.

4. Teknik nalisis data

Teknik analisis data yang digunakan oleh peneliti adalah secara interaktif yang dikemukakan oleh miles dan huberman. Miles dan Huberman (1984) dalam Sugiyono (2019: 321) mengemukakan bahwa aktivitas dalam analisis kualitatif dilakukan secara interaktif dan berlangsung secara terus-menerus sampai tuntas sehingga datanya jenuh.

Langkah-langkah dalam analisis data secara interaktif (interactive model) adalah sebagai berikut:

a. Data Collection

Pengumpulan data pada penelitian ini adalah dengan wawancara. Wawancara dilakukan pada pedagang sayur di pasar kidul dusun Blokagung. Wawancara dilakukan dengan mengajukan beberapa pertanyaan agar peneliti bisa mendapatkan data yang banyak sesuai tolok ukur data yang dibutuhkan.

b. Data Reduction

Pada tahap ini data dan informasi yang telah didapatkan diolah kembali menjadi lebih sederhana. Mereduksi data berarti merangkum, memilih hal-hal yang pokok, memfokuskan pada hal-hal yang penting, kemudian dicari tema dan polanya (Sugiyono, 2019: 323).

c. Data Display

Penyajian data merupakan merupakan salah satu dari teknik analisis data kualitatif. Penyajian data adalah kegiatan ketika sekumpulan informasi disusun, sehingga memberi kemungkinan akan adanya penarikan kesimpulan. Bentuk penyajian data kualitatif berupa teks naratif yang berbentuk catatan lapangan Sugiyono (2017:249). 


\section{Hasil Dan Pembahasan}

1. Ragam Bahasa Dalam Ranah Fonologi

Ragam bahasa atau variasi bahasa terjadi karena adanya anggota masyarakat penutur bahasa yang beragam. Dalam sebuah pasar yang ramai akan pengunjung sebagai pembeli terhadap para penjual di pasar, maka akan dijumpai suatu ragam bahasa dari penjual dan pembeli di pasar yang terkadang memakai bahasa yang berbeda.

Salah satu jenis pedagang, yaitu pedagang sayur juga menggunakan suatu ragam bahasa dalam menawarkan dan berkomunikasi dengan pembeli. Dapat dilihat pada pembahasan berikut ini bahwa terdapat ragam bahasa pedagang sayur di pasar kidul Dusun Blokagung, yaitu suatu tuturan yang berubah dari Bahasa Indonesia menjadi Bahasa Jawa yang dapat di kaji dalam ranah fonologi mulai dari asal katanya sampai pada perubahan yang diperlihatkan pada hasil tuturan oleh pedagang sayur, mulai dari penambahan fonem, penghilangan fonem, dan perubahan fonem.

1. Monolog Pedagang

Pada monolog pedagang terdapat perubahan fonem dan penghilangan fonem, yaitu akan dijelaskan dalam pembahasan sebagai berikut.

"sayor buk, monggo"

(sayur buk, ayo)

Kata "sayor" berasal dari Bahasa Indonesia sayur. Kata sayur mengalami perubahan fonem vokal $[\mathrm{u}]$ menjadi fonem vokal [o]. Sehingga kata

Bahasa Indonesia "sayur" menjadi kata Bahasa Jawa "sayor". Proses perubahan fonem ini dinamakan proses netralisasi karena terjadi karena pengaruh lingkungan.

\section{"Kangkong buk?"}

(kangkung buk?)

Kata "kangkong" berasal dari Bahasa Indonesia kangkung. Kata kangkung mengalami perubahan fonem vokal [u] menjadi fonem vokal [o]. Sehingga kata "kangkung" dalam Bahasa Indonesia berubah menjadi "kangkong" dalam Bahasa Jawa. Proses perubahan ini dinamakan proses naturalisasi karena perubahan terjadi akibat pengaruh lingkungan. 
Ciper buk, jarang enten, niki mumpung enten.

(kecipir buk, jarang ada, ini mumpung ada)

Ciper mbak? Rongewuan ae wes gawe samean.

(kecipir mbak? Dua ribuan saja buat samian)

Kata "kecipir" dalam Bahasa Indonesia berubah menjadi kata "ciper" dalam Bahasa Jawa. "Kecipir" mengalami penghilangan fonem /k/ dan /e/ sehingga menjadi kata "cipir". Proses penghilangan fonem ini dinamakan aferesis, yaitu proses penghilangan fonem satu atau lebih fonem pada awal kata. Kemudian kata “cipir” mengalami perubahan lagi, yaitu perubahan fonem vokal /i/ menjadi fonem vokal /e/. Hal ini dinamakan proses naturalisasi, yaitu perubahan fonem akibat pengaruh lingkungan

2. Dialog Pedagang

Dialog penjual dan pembeli terjadi ketika kegiatan tawar menawar harga berlangsung. Dari dialog tersebut dapat diketahui bahwa terdapat perubahan fonem, penghilangan fonem, dan penambahan fonem yang akan di jelaskan dalam pembahasan sebagai berikut.

$$
\begin{gathered}
\mathrm{Pb} \text { : piro yu sekilo? } \\
\text { (berapa satu kilo?) } \\
\mathrm{Pj} \text { : timon? Telungewu } \\
\text { (timun? Tiga ribu) }
\end{gathered}
$$

$\mathrm{Pb}$ : lha wingi kae sek rongewu nhe yu

(lha kemarin masih dua ribu mbak)

$\mathrm{Pj}$ : yo wes mundak neh, lha kulakku rongewu setengah

(ya sudah naik lagi, lha belanjaku dua ribu setengah)

$\mathrm{Pb}$ : yo sekilo ae yu

(ya satu kilo aja mbak)

$\mathrm{Pj}$ : yo kuwi njupuko sak kresek

(ya itu kamu ambil satu kresek)

Dalam dialog tersebut dapat diambil satu kata, yaitu "satu kilo" dalam Bahasa Indonesia kemudian menjadi kata "sekilo" dalam Bahasa Jawa. Kata "satu kilo" mengalami penghilangan fonem karena untuk upaya penghematan pengucapan. Kata satu kilo mengalami penghilangan fonem yaitu /t/ dan /u/, sehingga menjadi 
kata sakilo. Proses ini dinamakan zeroisasi sinkop karena penghilangan fonem berada di tengah kata. Kemudian untuk menjadi kata "sekilo", kata "sakilo" mengalami perubahan fonem vokal /a/ menjadi fonem vokal /e/. Sehingga kata "sakilo" menjadi kata "sekilo". Proses ini dinamakan netralisasi karena perubahan bunyi terjadi akibat pengaruh lingkungan.

$P b$ : teronge piro iki yu?

(terongnya berapa ini mbak?)

Pj: siji sewu mangatos yu kuwi isine telu.

(satu seribu limaratus mbak itu isinya tiga)

$\mathrm{Pb}$ : loro rongewu ngono lho yu.

(dua dua ribu gitu lho mbak)

Pj: lah yo ojo, ra oleh bati aku. Kulakku sewu, urong perjalanane barang. Ra oleh bati aku yu.

(ya jangan, tidak dapat untung saya. Belanjaku seribu, belum perjalanannya juga.

Tidak dapat untung saya)

Pb: yo gawe ngijoli perjalanane njupuk teko liyane.

(ya buat gantiin perjalanannya ambil dari yang lain)

Pj: sewu mangatos kuwi wes mourah lho yu. Neng liyane paleng regane malah rongewu siji.

(seribu limaratus itu sudah murah mbak, di yang lain harganya dua ribu satu) Pb: mosok to yu? Yo wes aku tuku loro ae. Dadi telung ewu yo yu. (masa iya mbak?. Ya sudah beli dua saja. Jadi tiga ribu ya mbak)

Kata "mangatos" berasal dari Bahasa Jawa "limangatus" dan berasal dari Bahasa Indonesia "lima ratus". Kemudian kata "limangatus" mengalami penghilangan fonem /// dan /i/ sehingga menjadi kata "mangatus". Proses ini dinamakan zeroisasi aferesis, yaitu penghilangan fonem di awal kata. Kemudian kata "mangatus" mengalami perubahan fonem vokal /u/ menjadi /o/. Sehingga kata "mangatus" menjadi kata "mangatos". Proses perubahan fonem ini dinamakan proses netralisasi, yaitu perubahan fonem akibat pengaruh lingkungan.

Kata "mourah" berasal dari Bahasa Indonesia "murah". Kata "murah" mengalami penambahan fonem /o/. Sehingga kata "murah" menjadi kata "mourah". Proses 
penambahan fonem ini dinamakan proses diftongisasi, yaitu perubahan bunyi vokal tunggal (monoftongisasi) menjadi bunyi vokal rangkap (diftongisasi).

$\mathrm{Pj}$ : tumbas sayor opo mbak, samean mileh sek.

(beli sayur apa mbak?. Samian milih dulu)

$\mathrm{Pb}$ : pinten niki buk?

(berapa ini buk?)

Pj: opo mbak?. Keniker sewu mangatos kuwi mbak sak bunderan

(apa mbak?. Kenikir seribu limaratus itu mbak satu ikat)

$\mathrm{Pb}:$ mboten sewu ae to buk?

(tidak seribu saja buk?)

$\mathrm{Pj}$ : ra oleh mbak, ra bati buk e

(tidak boleh mbak, tidak untung ibuk)

Kata "sayor" berasal dari Bahasa Indonesia sayur. Kata sayur mengalami perubahan fonem vokal /u/ menjadi fonem vokal /o/. Sehingga kata Bahasa Indonesia "sayur" menjadi kata Bahasa Jawa "sayor". Proses perubahan fonem ini dinamakan proses netralisasi karena terjadi karena pengaruh lingkungan.

Kata "milih" dalam Bahasa Indonesia mengalami perubahan pada Bahasa Jawa yaitu perubahan fonem vokal /i/ menjadi fonem vokal /e/. Sehingga kata "milih" menjadi kata "mileh". Hal ini disebabkan adanya proses naturalisasi, yaitu proses perubahan fonem karena akibat pengaruh lingkungan.

Kata "keniker" berasal dari bahasa indonesia "kenikir". Kata "kenikir" mengalami peubahan fonem vokal [i] menjadi fonem vokal [e]. Sehingga kata "kenikir dalam bahasa indonesia berubah menjadi "keniker" dalam bahasa jawa. Proses perubahan ini dinamakan proses naturalisasi karena perubahan terjadi akibat pengaruh lingkungan.

Kata "mangatos" berasal dari bahasa jawa "limangatus" dan berasal dari bahasa indonesia "lima ratus". Kemudian kata "limangatus" mengalami penghilangan fonem [1] dan [i] sehingga menjadi kata "mangatus". Proses ini dinamakan zeroisasi aferesis, yaitu penghilangan fonem di awal kata. Kemudian kata "mangatus" mengalami perubahan fonem vokal [u] menjadi [o]. Sehingga kata "mangatus" menjadi kata "mangatos". Proses perubahan fonem 
ini dinamakan proses netralisasi, yaitu perubahan fonem akibat pengaruh lingkungan.

2. faktor yang mempengaruhi ragam bahasa

1. faktor kebiasaan

Penggunaan bahasa pada tuturan pedagang sayur lebih terlihat seperti kebiasaan yang sudah turun-temurun dalam menawarkan barang dagangannya. Dari hal kebiasaan inilah yang menyebabkan sebuah bahasa yang digunakan kurang sesuai dengan kaidah bahasa yang sebenarnya. Para pedagang menggunakan bahasa yang mudah dipahami tanpa memperdulikan bahasa tersebut sudah benar atau belum. Karena kebiasaan yang sudah sering digunakan tidak dapat dihilangkan atau tidak dapat dirubah dengan yang baru.

2. Faktor menarik perhatian pembeli

Sebagai pedagang yang menginginkan barang dagangannya laku terjual dengan cepat, maka sebagai penjual harus pandai menarik perhatian pembeli. Begitulah yang dilakukan para pedagang untuk menarik perhatian pembeli dengan menggunakan bahasa yang berbeda dari pedagang yang lain. Misalnya, pedagang lebih menggunakan bahasa indonesia yang dapat dipahami oleh semua orang. Ketika orang paham dengan bahasa yang digunakan maka pembeli akan tetarik untuk mampir dan membeli kebutuhannya.

3. Faktor agar cepat terjual

Semua pedagang mengharapkan dagangannya laku terjual, maka pedagang akan melakukan berbagai cara untuk menawarkan dagangannya pada para pembeli. Biasanya pedagang menawarkan barang dagangannya agar cepat laku terjual adalah dengan cara memuji daganagnnya sendiri. Seperti hasil data yang telah dipaparkan, yaitu:

- "tumbas opo mbak?, kene sayure jek podo seger"

- “ayo mbak lomboke jek apik-apik”

\section{Kesimpulan}

1. Ragam bahasa pedagang sayur dalam ranag fonologi 
Ragam bahasa dalam ranah fonologi pada tuturan pedagang sayur di pasar kidul dusun Blokagung, mengalamai beberapa perubahan bunyi. Baik berupa penambahan fonem, penghilangan fonem, maupun perubahan fonem.

a. perubahan fonem, misalnya pada kata "kangkung" yang berasal dari kata bahasa indonesia yaitu "kangkung", maka dapat menjadi kata kangkung karena melalui proses perubahan fonem naturalisasi yaitu dari fonem $[\mathrm{u}]$ menjadi [o].

b. penghilangan fonem, misalnya pada kata "molas" yang asal katanya berupa limolas. untuk menjadi kata molas, kata lomolas mengalami penghilangan fonem yaitu berupa fonem [1] dan [i], sehingga disebut zeroisasi aferesis, yaitu penghilangan fonem di awal kata.

c. penambahan fonem, misalnya pada kata "mourah" yang berasal dari kata "murah". kata tersebut mengalami penambahan fonem [o], sehingga disebut proses diftongisasi, yaitu berubahnya bunyi vokal tunggal menjadi bunyi vokal rangkap.

2. Faktor yang mempengaruhi ragam bahasa pedagang sayur

Dalam kegiatan perdagangan, maka akan terdapat sebuah cara untuk membuat dagangannya menjadi cepat terjual. Sebagai pedagang cara yang dapat membuat dagangannya cepat terjual adalah dengan cara menawarkan pada setiap pembeli yang melintas. Untuk menawarkansebuah dagangan, penjual menggunakan ciri khas bahasa tersendiri. Ditemukan tiga faktor yang mempengaruhi ragam bahasa pada pedagang sayur di pasar kidul dusun Blokagung, yaitu faktor kebiasaan, faktor menarik perhatian pembeli dan faktor cepat terjual.

\section{Daftar Rujukan}

Asngadi Rofiq, K. A. N. (2021). Proses Morfologis Reduplikasi dalam Buku Generasi Optimis Karya Ahmad Rifa'i Rif'an. PENEROKA, 1(01), 42-59.

Muslich, Masnur. 2014. Fonologi Bahasa Indonesia. Jakarta: Bumi Aksara. Sugiyono. 2016. Metode Penelitian Kuantitatif, Kualitatif, Dan R\&D. Bandung: Alfabeta.

Malabar, Sayama. 2015. Sosiolinguistik. Gorontalo: Ideas Publishing. 
Zaim, M. 2014. Metode Penelitian Bahasa. Padang: Sukabina Press.

Ainurrahma, Isti. 2013. Ragam Bahasa Dan Strategi Tindak Tutur Pedagang Asongan Di Terminal Minak Koncar Kabupaten Lumajang. Skripsi. Jember: Program Studi Pendidikan Bahasa Dan Sastra Indonesia Fkip Universitas Jember.

Chaer, Abdul. 2014. Linguistik Umum. Jakarta: Pt Rineka Cipta.

Kbbi : 2020. Kamus Besar Bahasa Indonesia. (Online). Tersedia Di Kbbi.Kemdikbud.Go.Id. Diakses 3 Juni 2020.

Muslich, Masnur. 2018. Fonologi Bahasa Indonesia. Jakarta: Bumi Aksara. Mahsun. 2014. Metode Penelitian Bahasa. Jakarta: Rajawali Pers.

Verhaar. 2012. Asas-Asas Linguistik Umum. Yogyakarta: Gadjah Mada University Press.

Moleong. 2016. Metodologi Penelitian Kualitatif. Bandung: Remaja Rosdakarya. 